\title{
Usage of Scanning Electron Microscopy for Particulate Matter Sources Identification
}

\author{
Roman Ličbinský*, Aleš Frýbort, Jiří Huzlík, Vladimír Adamec, Karel Effenberger \\ Transport Research Centre, Brno, Czech Republic \\ *Corresponding author: roman.licbinsky@cdv.cz
}

Pavel Mikuška, Martin Vojtěšek, Kamil Křůmal

Institute of Analytical Chemistry AS CR, v. v. i., Brno, Czech Republic

DOI: $10.2478 / \mathrm{v} 10158-010-0019-8$

\begin{abstract}
Particulate matter (PM) diameter and shape are the most discussed physical properties considering behaviour characterisation, source identification, and possible effects on human health. Some groups of particles not only have a typical chemical composition but also a specific shape reflecting the method of their formation, so it is possible to deduce the source. A scanning electron microscope VEGA TS 5136 LSU (Tescan, s.r.o., Czech Republic) was used for PM imaging. PM air samples were captured on Millipore special filters made of polycarbonate membrane (Isopore) with a $0.6 \mu \mathrm{m}$ size of pores. PM samples were taken both from near the exhaust of gasoline and diesel engines to define PM shapes emitted from combustion processes in vehicles, and also from chosen localities that represent urban sites with different traffic intensity and with different possible PM sources (transportation, industry). Samples of street dust were also collected by sweeping with a broom and with a vacuum cleaner to identify PM generated by resuspension. Separate spherical particles were observed on exposed filters near a gasoline vehicle's exhaust pipe and their aggregates near a diesel vehicle's exhaust. Spherical particles aggregates were also observed on filters exposed at a locality with a high traffic intensity where road traffic is considered to be the dominant source of air pollution. Larger spherical particles that represent the products of coal combustion were found at a locality near an industrial area. Other particle shapes, excluding spherical particles, were often observed at the localities that represent a more open area with more trees. Sharp-edged particles of geological origin (soils) and larger spherical or elongated particles of biological origin (spores) were also often observed on the filters from these localities which is evidence of a significant contribution of other processes to the overall PM air pollution, namely resuspension.
\end{abstract}

KEYWORDS: Particulate Matter, Morphology, Scanning Electron Microscopy, Sources.

\section{INTRODUCTION}

Particulate matter (PM) is considered to be a mixture of chemical components originating from a variety of sources with specific physical parameters (such as shape, diameter, electric charge, solubility, surface of the particles) and chemical composition (organic and inorganic compounds). Sources, mechanisms of formation, meteorological conditions, distance from the source and other conditions determine these basic parameters (US EPA, 2004a, US EPA, 2004b). Knowledge about the physical properties of particles is important 
for the characterization of their behaviour, source identification, and possible health risks. The diameter and the shape are the most discussed from this point of view, because these properties determine PM hazardousness. The shape determines the PM incidence on the cell walls of the respiratory system, and the diameter determines whether the particle can be inhaled and in which part of the respiratory system it can be deposited (Weijer et al., 2001). Coarse particles and parts of fine particles $(2-10 \mu \mathrm{m})$ are deposited in the extra-thoracic and the trachea-bronchial areas, while particles smaller than $1 \mu \mathrm{m}$ penetrate into the pulmonary alveoli and can be deposited there. Many recent studies state in their conclusion clear evidence that air pollution by particulate matter significantly contributes to an increase in the risk of respiratory symptoms and diseases and risk of death due to cardiopulmonary causes, especially in the population of children younger than five years (Dockery et al., 1994; Kunzli et al., 2000, Pope, et al., 2002; Krzyzanowsky et al., 2005). Knowledge about particles' shape and diameter obtained by the analysis of individual particles with an electron microscopy yields important information for accurate source identification and leads to a more complete estimation of exposure (Weinbruch, Ebert, 2004). Hence the electron microscopy is a very effective method for PM sources apportionment (McCullum, Kindzierski, 2001, Chong et al., 2002, Zonping et al., 2003, Casuccio et al., 2004, Chen et al., 2005, Senlin et al., 2008).

Research described in this paper involves the analysis of particulate matter loading in urban ambient air and was conducted to characterize source contributions to the overall PM air pollution with the primary interest in determining the transportation share.

\section{METHODS}

\subsection{PM and street dust sampling}

Middle volume aerosol samplers LECKEL MVS6 (Sven Leckel Ingenierbüro, Germany) equipped with inlets for the separate sampling of PM fractions, were placed at three different locations in an urban environment. The first locality was a street valley with high traffic intensity $(36,000$ vehicles per day) where road traffic is considered to be the dominant source of air pollution. The second one represents a more open area with family houses in surroundings with less traffic intensity $(9,000$ vehicles per day). The third locality is placed approx. $100 \mathrm{~m}$ far from the busy road and represents a residential neighbourhood with family houses with a lot of green areas close by. Industry is considered to be the dominant source of pollution due to an industrial area placed close by in the south-east of this locality. Local heating and soil resuspension could also significantly contribute to PM air pollution at the last two localities. PM sampling was carried out during the summer and winter seasons. Filters were exposed for 1 hour to capture only one layer of particles which is suitable for shape observations. PM air samples were taken with the special Millipore filters made of polycarbonate membrane (Isopore) with the $0.6 \mu \mathrm{m}$ size of pores with perfectly smooth surface designed specially for the scanning electron microscopy (SEM) purposes. To define more precisely particles produced by fossil fuel combustion in vehicle engines in chosen localities, PM were captured using low volume samplers Aircheck2000 (SKC inc., USA) next to the vehicles' exhaust pipe (cca. $2 \mathrm{~cm}$ distance). The measurement was carried out for a comparison of both gasoline engine (Opel Astra 1.6 1. manufactured in 2000, covered distance 291,779 km) and diesel engine (Škoda Octavia 1,9 TDi, manufactured in 2005 , covered distance $85,099 \mathrm{~km}$ ). Samples of street dust were collected by sweeping with a broom and with a vacuum cleaner next to the road at the first locality and also from a parking place next to the family house in the third locality to identify PM generated by resuspension. The street dust was then fractionated into 3 size intervals $100-400 \mu \mathrm{m}, 50$ - 
$100 \mu \mathrm{m}$ and $\leq 50 \mu \mathrm{m}$. Particles smaller than $50 \mu \mathrm{m}$ can be removed from the surface by wind or turbulence caused by moving vehicles.

\subsection{SEM analysis}

Imaging of PM was carried out using the scanning electron microscope VEGA TS 5136 LSU (Tescan s.r.o., Czech Republic) that permits both a low vacuum and a high vacuum mode of measurements with a resolution up to $3.5 \mathrm{~nm}$. The surfaces of the exposed filters and street dust samples placed on the carbon plaster were coated with a 20 nanometres thin layer of gold to divert the arising charge from the place of the impact of the electron beam by using the device Bal-Tec SCD 050 (Bal-Tec, Lichtenstein). This permits imaging of the PM at a magnification of 100 thousand at a very good quality, suitable for the precise determination of the PM shape. Prepared samples were observed in high vacuum mode $(0.02 \mathrm{~Pa})$ with a cathode high voltage of $30 \mathrm{kV}$. Low-energy secondary electrons that are ejected from the k-orbital of the specimen atoms by inelastic scattering interactions with beam electrons were used for imaging. The brightness of the signal depends on the number of secondary electrons reaching the detector. If the beam enters the sample perpendicular to the surface, then the activated region is uniform about the axis of the beam and a certain number of electrons are emitted from the sample. As the angle of incidence increases, the emission distance of one side of the beam will decrease, and more secondary electrons will be emitted. Thus steep surfaces and edges tend to be brighter than flat surfaces, which results in images with a well-defined appearance.

\section{RESULTS AND DISCUSSION}

Spherical particles were observed, as was expected, at the samples collected next to the exhaust pipes of both vehicles. The spherical particles are shown in fig. 1. Separate spherical particles produced by the combustion of fossil fuel in vehicles' engines (soot) are approx. $50 \mathrm{~nm}$ in diameter. PM emitted by the diesel engine create more aggregates of spherical particles growing up to $2 \mu \mathrm{m}$ in diameter (image on the right in fig. 1) whereas in gasoline engines exhaust gases PM are more isolated and aggregates are less common (image on the left in fig. 1).
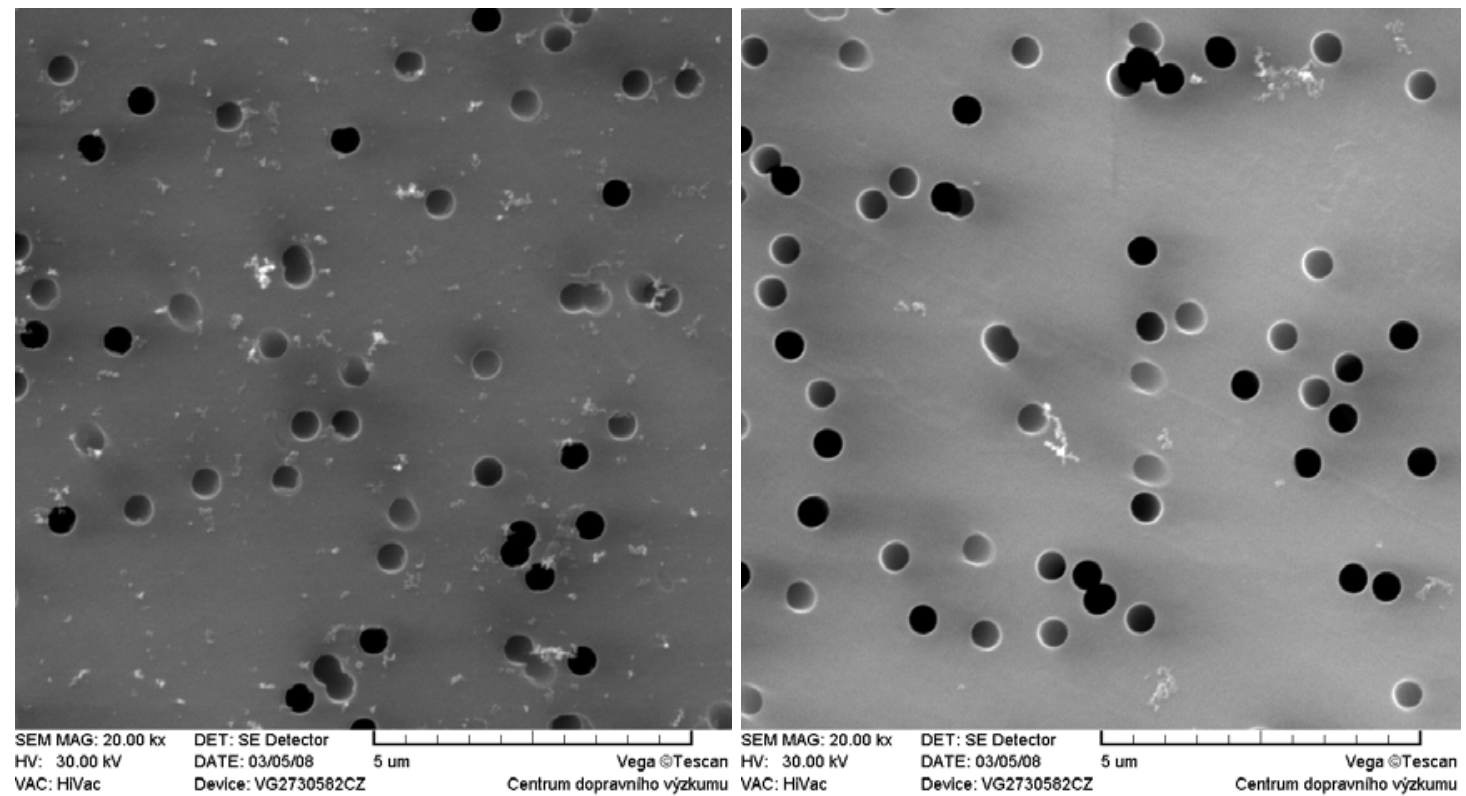

Figure 1: PM emitted by gasoline (on the left) and diesel engine (on the right). 
Street dust samples collected on localities 1 and 3 are represented entirely by sharp-edged particles in all fractions (image on the left in fig. 2). They are dominant especially in the size fraction smaller than $50 \mu \mathrm{m}$ that can be easily removed from a surface by the wind or the turbulence caused by moving vehicles. Fractions larger than $50 \mu \mathrm{m}$ also contain organic material particles, probably mechanically separated parts of plants (image on the right in fig. 2).

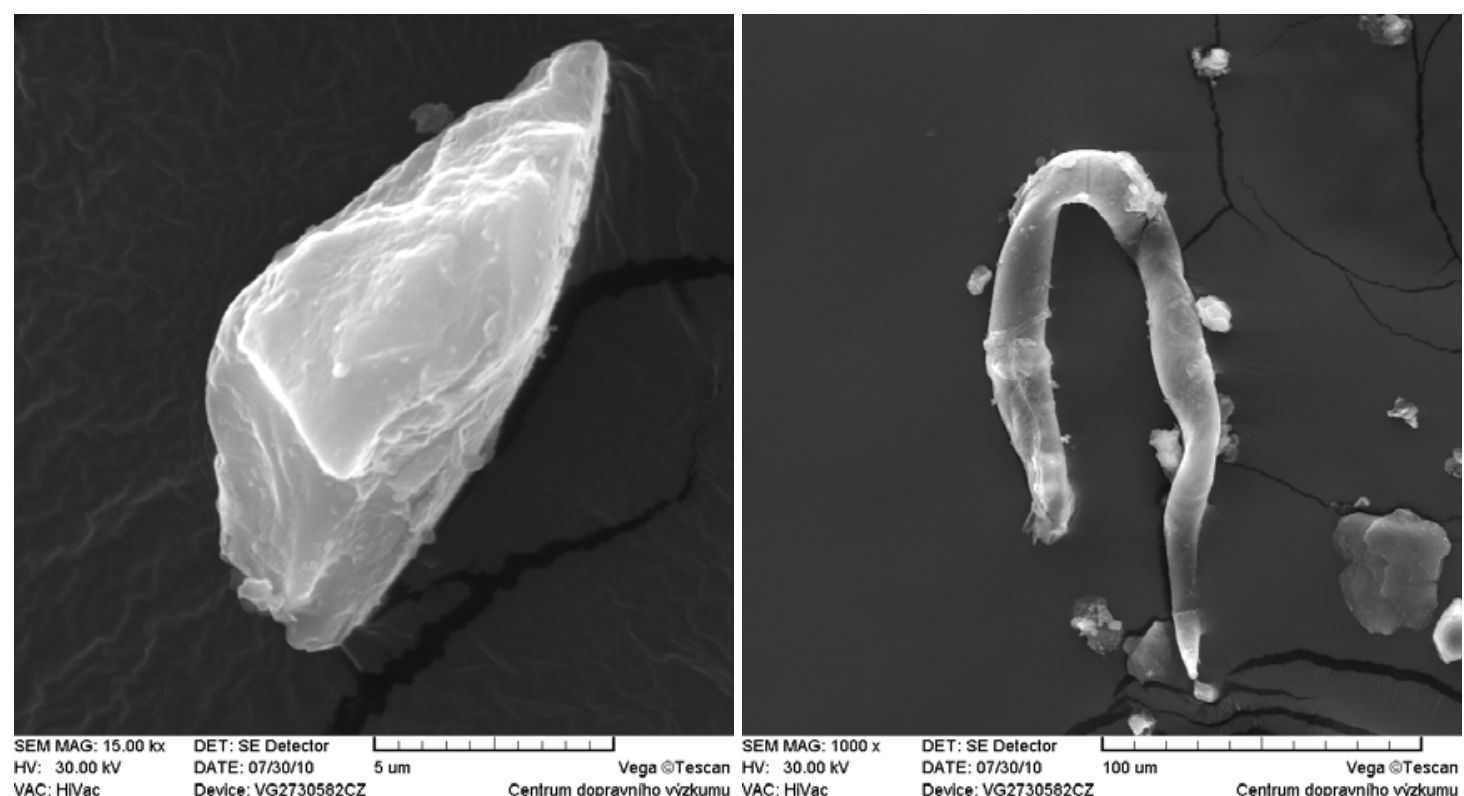

Figure 2: Street dust particle in fraction smaller than $50 \mu \mathrm{m}$ (on the left) and organic particle in street dust fraction $50-100 \mu \mathrm{m}$ (on the right).

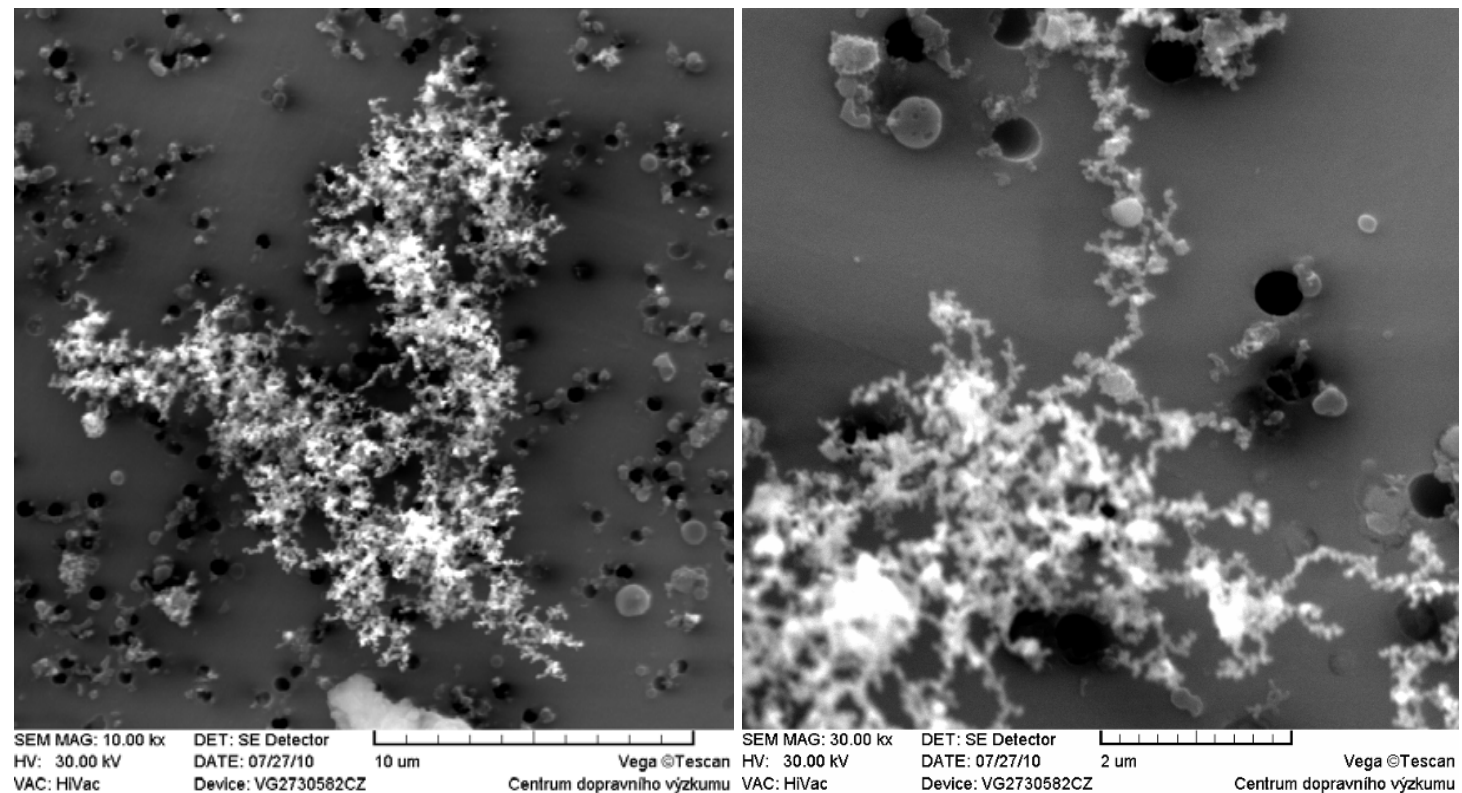

Figure 3: Spherical particles aggregates (on the left) and detail of the basic structural element (on the right).

Similar spherical particles (soot) as those captured next to exhaust pipes with a diameter of about $50 \mathrm{~nm}$ coagulated to the larger aggregates were the most frequently observed ones in the samples of ambient air taken on the first locality with high traffic intensity 
during both sampling seasons (fig. 3). This fact indicates the traffic as a dominant source of air pollution by PM at this site. Diameters of these aggregates are up to $20 \mu \mathrm{m}$, which indicates their origin in the atmosphere far away from exhaust pipes.

Sharp-edged and cubic or cubical particles were also observed on filters exposed on the first locality. The abrasion of vehicles break-shoe lining and stressed bodies parts (image on the left in fig. 4) or wear of tyres, road pavement or parts of material (sodium chloride) used for the road maintenance in winter season (image on the right in fig. 4) could be the sources of these particles.

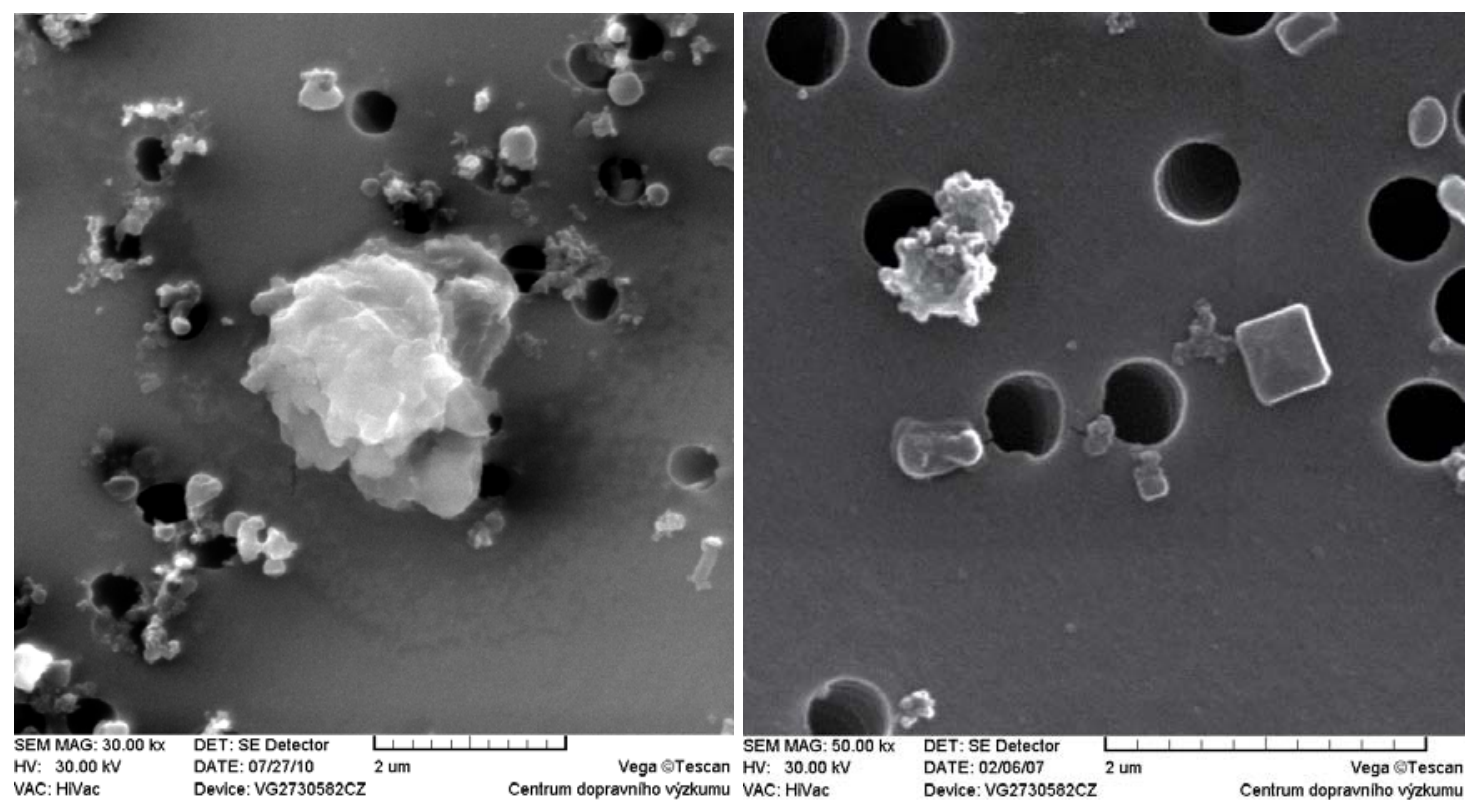

Figure 4: Particle mechanically separated from highly stressed car accessories (on the left) and cubic particle of material used for road maintenance (on the right).

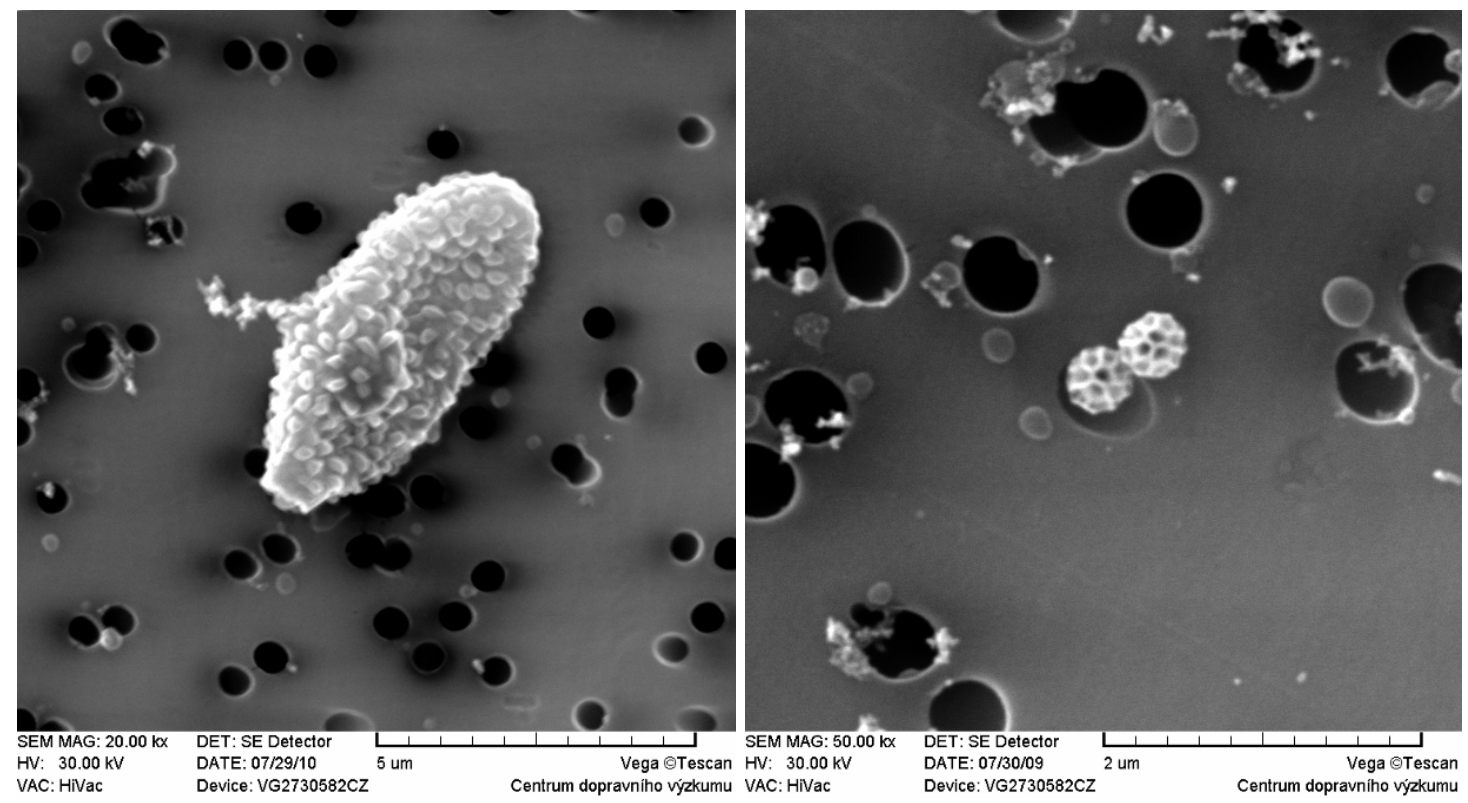

Figure 5: Particles of biological origin. 
Biological particles were also found on filters exposed during the summer sampling campaign on this locality, namely in coarse PM fraction, PM10 (image on the left in fig. 5), but several of them were also observed in smaller PM2.5 fraction. The image on the right in fig 5 shows brochosomes cover which is produced by leafhoppers (Cicadellidae) (Shi et al., 2003, Casuccio et al., 2004).

The same particle types as in locality 1 were also observed on the other localities but in different shares of the total amount. Spherical particles with a diameter of about $50 \mathrm{~nm}$ coagulated to the larger aggregates (soot) were also found on the second and the third locality but in much smaller amount than at locality 1. Apart from these spherical particles larger spherical particles were often observed with a diameter of between 0.5 and $1.5 \mu \mathrm{m}$ on filters exposed in locality 3 (fig. 6). These particles represent fly ash from industrial production near this locality and prove thus the significant contribution of this source to overall PM air pollution in this locality.

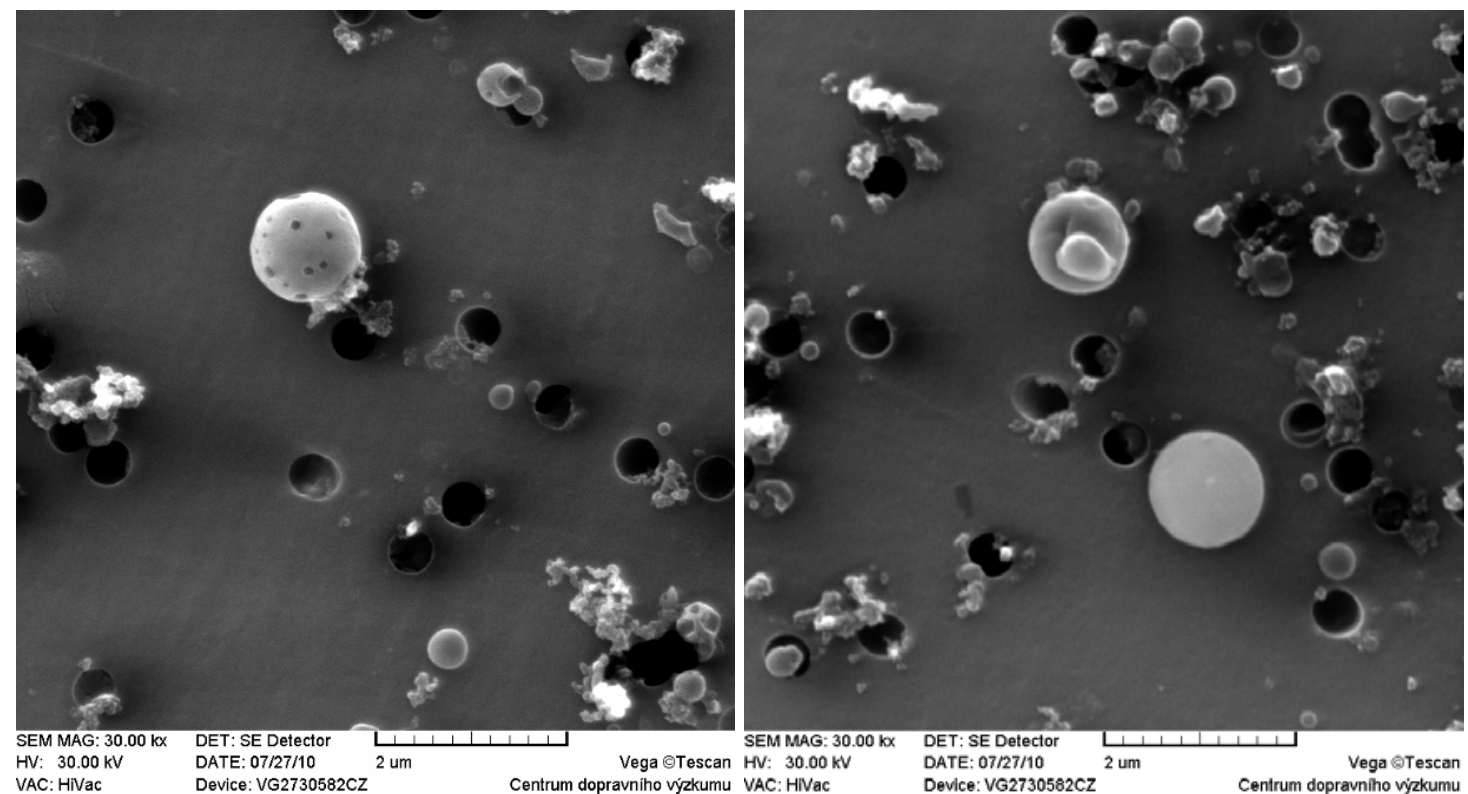

Figure 6: Particles from industrial production.

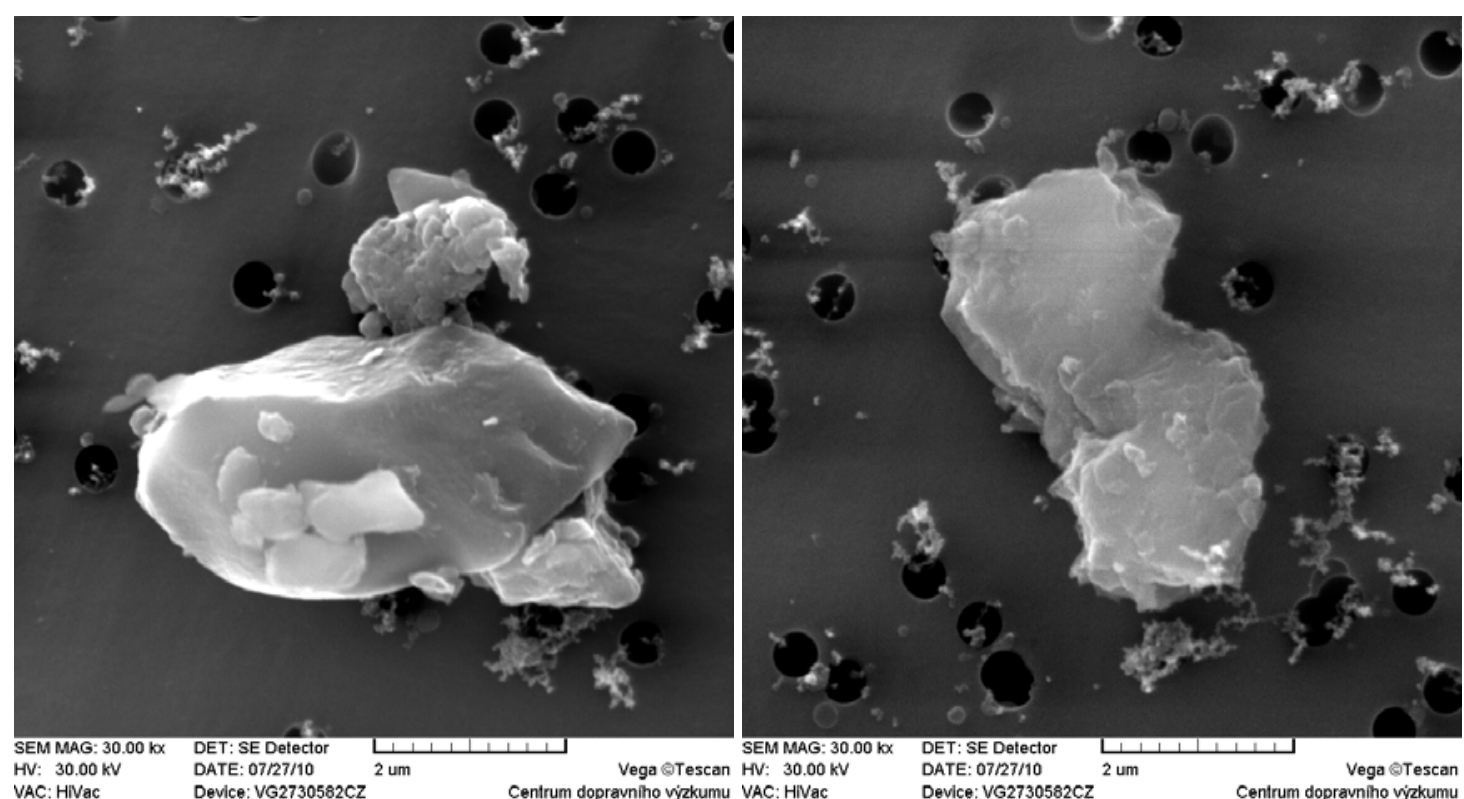

Figure 7: Resuspended geological particles. 
Sharp-edged particles significantly occurred on filters exposed at locality 2 and 3, more wide open areas with more greenery. These particles are very similar to those observed in collected street dust samples and hence represent particles of geological origin resuspended from the surface (fig. 7).

The occurrence of these particles proves the significant contribution of other sources to overall PM air pollution on the second and the third locality, particularly the resuspension processes and industrial emissions (i.e., coal combustion) with the exception of transportation (i.e., fuel combustion).

\section{CONCLUSIONS}

Several sources contributing to overall PM air pollution were found at chosen localities on the basis of image observations using SEM. Fuel combustion processes are the dominant source of PM pollution at locality 1 with a high traffic intensity and are represented by spherical particles with a diameter of about $50 \mathrm{~nm}$, coagulated to the larger aggregates (soot). Sharp-edged particles representing abrasion of vehicles' break-shoe lining and stressed bodies' parts or geological particles resuspended from the surface also significantly occurred at this locality. Resuspension seems to be the dominant source of PM air pollution at localities 2 and 3; however, coal combustion at the industrial area near locality 3 significantly contributes to $\mathrm{PM}$ air pollution and is represented by larger $(0.5-1.5 \mu \mathrm{m}$ in diameter $)$ spherical particles (fly ash).

Scanning electron microscopy (SEM) is an effective tool (cheaper and faster than chemical analysis) for the identification of PM sources. However, for more proper PM sources identification it is suitable to combine the knowledge on separate PM morphology with the chemical composition of PM by association of SEM with an Energy Dispersive X-ray analyzer that allows the measurements of elements concentrations in micro volume of the solid materials. PM origin interpretation only on the basis of morphology characterization without the chemical composition knowledge could, in some cases, be inaccurate or misleading. Therefore the obtained results presented in this paper were compared with data published in scientific literature and impact journal articles in which the same PM shapes were observed and assigned to a specific source, also on the basis of chemical composition, and correlate well with them.

\section{ACKNOWLEDGEMENTS}

The study was supported by the Czech Ministry of Transport within research intention project No. 04499457501 "Sustainable Transport - Chance for the Future, part 5 Transport and Environment" and by Ministry of the Environment of the Czech Republic under R\&D project No. SP/1a3/55/08 "Morphology, chemical and toxicological characterisation of road dust and particulate matter including sources apportionment" and by the Institute of Analytical Chemistry of ASCR under an Institutional research plan No. AV0Z40310501.

\section{REFERENCES}

Casuccio, G. S., Schlaegle, S. F., Lersch, T. L., Huffman. G. P., Chen, Y., Shah, N. 2004. Measurement of fine particulate matter using electron microscopy techniques. Fuel Processing Technology. vol. 85, pp. 763-779.

Chen, Y., Shah, N., Huggins, F. E., Huffman, G. P. 2005. Microanalysis of ambient particles from Lexington, KY, by electron microscopy. Atmospheric Environment. vol. 40, pp. 651- 
663.

Chong, N., Sivaramekrishnan, K., Wells, M., Jones, K.: 2002. Characterization of Inhalable Particulate Matter in Ambient Air by Scanning Electron Microscopy and EnergyDispersive X-ray Analysis. EJAFChe. vol. 3, pp. 145-164.

Dockery, D.W., Pope, C.A.: 1994, Acute respiratory effects of particulate air pollution. Ann. Rev. Public Health, vol. 15, pp. 107-132.

Krzyzanowsky, M., Kuna-Dibbert, B., Schneider, J. (Eds.) 2005. Health effects of transportrelated air pollution. WHO Europe. 190 p., ISBN 92-890-1373-7.

Kunzli, N., Kaiser, R., Medina, S., Studnicka, M., Chanel, O., Filliger, P., Herry, M., Horak, F., Puybonnieux-Texier, V., Quenel, P., Schneider, J., Seethaler, R., Vergnaud, J.C., Sommer, H.: 2000. Public-health impact of outdoor and traffic-related air pollution: a European assessment. The Lancet, vol. 356, pp. 795-801.

Martuzzi, M., Galassi, C., Ostro, B., Forastiere, F., Bertollini, R.: 2002. Health impact assessment of air pollution in the eight major italien cities. WHO, 65 p. ISBN 92-8901085-1.

McCullum, K., Kindzierski, W.: 2001. Analysis of particulate matter origin in ambient air at High Level, Alberta. Department of Civil \& Environmental Engineering, University of Alberta, Edmonton, Alberta. 35 p. ISBN 1-55261-126-4.

Pope, C.A., Burnett, R.T., Thun, M.J., Calle, E.E., Krewski, D., Ito, K., Thurston, G.D.: 2002. Lung cancer, cardiopulmonary mortality, and long-term exposure to fine particulate air pollution. JAMA, vol. 287, pp.1132-1141.

Reid, J. S., Jonsson, H. H., Maring, H. B., Smirnov, A., Savoie, D. L., Cliff, S. S., Reid, E. A., Livingston, J. M., Meier, M. M., Dubovik, O., Tsay, S. Ch.: 2003. Comparison of size and morphological measurements of coarse mode dust particles from Africa. Journal Of Geophysical Research, vol. 108(D19), 8593, DOI:10.1029/2002JD002485.

Senlin, Lu., Zhenkun, Y., Xiaohui, C., Minghong, W., Guoying, S., Jiamo, F., Paul, D.: 2008. The relationship between physicochemical characterization and the potential toxicity of fine particulates (PM2.5) in Shanghai atmosphere. Atmospheric Environment vol. 42, pp. 7205-7214.

Shi, Z., Shao L., Jones, T.P., Whittaker, A.G., Lu, S., Bérubé, K.A., He, T., Richrads, R.J.: 2003. Characterization of airborne individual particles collected in an urban area, a satellite city and a clean air area in Beijing, 2001. Atmospheric Environment vol. 37, pp. 4097-4108.

Weijer, E. P., Even A., Kos, G.P.A., Groot, A.T.J., Erisman, J.W., ten Brink, H.M.: 2001. Particulate matter in urban air: health risks, instrumentation and measurements and political awareness, ECN-Clean Fossil Fuels Air Quality, 68 p., ECN-R--01-002.

Weinbruch, S, Ebert, M. 2004. Source apportionment of atmospheric aerosols based on electron microscopy, Technical University of Darmstadt.

Zongping, P., Baoping, H., Hanhu, L., Xiaoyan, J., Hongyan, H., Yunjian, L.: 2003. Study on Application of SEM in Source Apportionment for Urban Ambient Particulate Matter, China University of Mining \& Technology, Xuzhou.

US EPA 2004a. Air Quality Criteria for Particulate Matter Vol. 1. 900 p.

US EPA 2004b. Air Quality Criteria for Particulate Matter Vol. 2, 1148 p. 